دور الأنشطة الرياضية في شغل وقت الفراغ لدى المسنات في مدينة الرياض بالمملكة العربية السعودية بمركز الملك سلمان الاجتماعي

\author{
إعداد \\ بنحلاء مطلق السهلي \\ قسم الدراسات الاجتماعية \\ كلية الآداب- جامعة الملك سعود
}


إن ممارسة الرياضة هي مظهر من مظاهر تقدم البحتمع و مؤشرا مهم على ارتفاع المستوى المعيشي والثقافي في البحتمع فالرياضية أحد معايير التقدم والتنمية في أي دولة، ويي ظل التطورات الكبيرة التي تشهدها المملكة العربية السعودية ، والتغيرات الاقتصادية والاجتماعية والتكنولوجية وإنعكاسها على واقع الحياة الاجتماعية، بما فيها التغير الذي طرأ على وسائل الترويح الحديثة نفسها وتعددت المراكز والنوادي والمقاهي لكلا الفئتين من الذكور والإناث، الإ أها تغافلت فئة كبار السن، إذا لا يوجد مركز ترفهي لهم سوى مركز الملك سلمان الاجتماعي في مدينة الرياض.

بالرغم من أهمية هذه الفئة العمرية وتزايد أعدادهم و توفر وقت فراغ كبير في حياة المسنات إذ تمدر ساعات كبيرة من الوقت بلا فائدة أو هدف محدد، لذا يجب إيجاد وسيلة مناسبة لشغل وقت فراغهن ومساعدهن على القيام بذلك وإيجاد خطة مناسبة لإستثمار وقت الفراغ ، يتمثل هذا في إشراكهن في الأنشطة الرياضية المختلفة وتشجعهن على الاستمرار فيها، لما لتلك الأنشطة من فوائد في تحسين الصحة النفسية والجسدية، وتحديد الروح المعنوية والتقليل من الملل والضجر، وإضفاء المرح والمتعة إلى حياتن. وتعمل الانشطة الرياضية والحركية على تحسين الصحة النفسية والجسدية للمسنات ،لذلك تعتبر ضرورة ملحة لهن في هذه المرحلة العمرية الحساسة ، حيث أن النشاط البدني يحقق للفرد حياة أفضل في أي مرحلة من عمره، فهو يعمل على تحسين وزيادة التوازن والقوة والتناسق والمرونة وقوة التحمل والوقاية من السقوط، الذي هو سبب رئيسي للتعوق بين كبار السن، كما تساعد على تقليل خسائر عن زيادة القوة العضلية والتوازن والحد من احتمالت التعرض لخطر" هشاشة العظام، ، وقد تبين أن معدل انتشار الأمراض النفسية بين ذوي النشاط البدني الأقل من غيرهم، مثل : المشي والسباحة والقيام برحلات أو ركوب الدراجات، فهي أنشطة متتازة يمكن أن يقوم بها كبير السن، و تساهم في بناء تقدير الذات والشعور بالثقة وتعزيز الصحة النفسية والاندماج في المجتمع

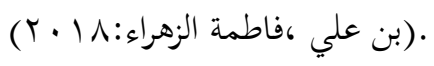

\section{موضوع الدراسة:}

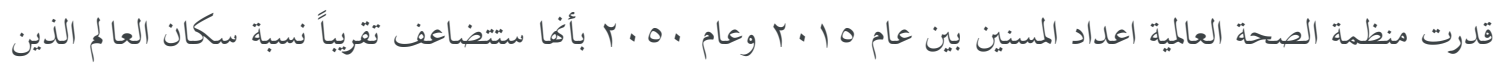

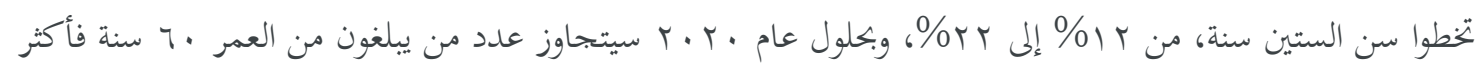

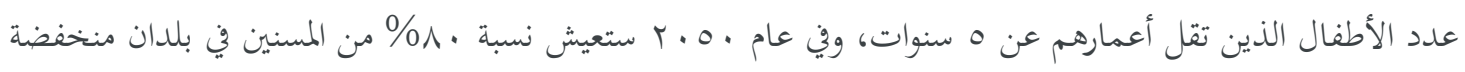

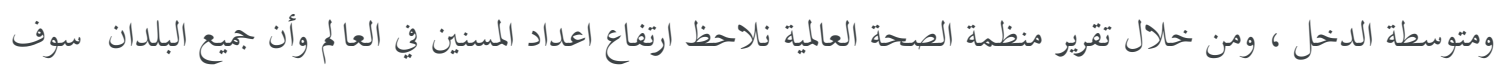

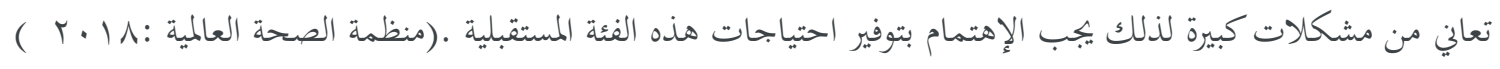
وكلما تقدم الإنسان في العمر أصبح معرضاً لإصصابة بالأمراض أكثر من غيره سواء الأمراض النفسية أو العقلية، أو الجسدية، والتي بدورها تؤثر على تواصل المسن مع المخيط الخارجي، وهذا ينعكس سلباً على حالته النفسية ويزيد من القلق والتوتر لديه من الحاضر والمستقبل، وخاصة إذا شعر المسن أو أشعره من حوله أنه لا فائدة منه ولا يرغبون في وجوده والتحدث معه، وبدأ يفقد قيمته وجدواه في الحياة، ويتزايد هذا الشعور في ظل غياب النشاط اليومي الذي يفرغ فيه طاقاته بالإضافة إلى غياب 
الشريك والأهل عن معترك حياته، وفقدان الأصدقاء بعد أن كانت تؤلف جزءاً كبيراً من نشاطه واهتماماته اليومية

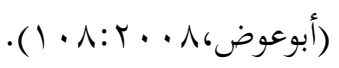

إن جميع هذه المشكلات التي يعاني منها المسنين بشكل عام والمسنات بشكل خاص، تشكل ضغط عليهن، وتحرمهن من متعة الاستفادة من المتبقي من حياتَ، لذلك يحتجن إلى وسيلة للتنفيس والترويح يجددن من خلالها نشاطهن وحيويتهن، وذلك من خلال بعض الأنشطة لقضاء وقت الفراغ الذي يقتحم حياته، وخاصة في ظل التغيرات التي طرأت على الأسرة السعودية من وجود الخادمات والسائقين، وتقلص دور المسنات داخل أسرهن، ولم يعد لهن فاعلية في الأسرة كما في السابق من ارتفاع مكانتهن والإمساك بزمام الأمور، بالإضافة إلى زواج الأبناء واستقلالهم، وأيضا عدم توفر المراكز أو المؤسسات الاجتماعية الخاصة بترفيه كبيرات السن في مدينة الرياض.

\section{مشكلة الدراسة Research problem}

قدرت الهيئة العامة للإحصاء أن عدد السكان كبار السن بالمملكة العربية السعودية (07 سنة فأكثر) بلغ ه . . 10 مليون مسن،

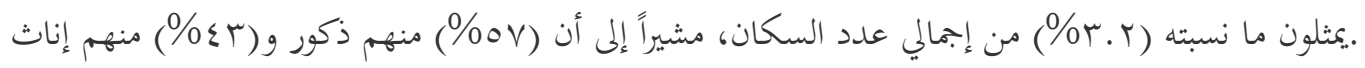

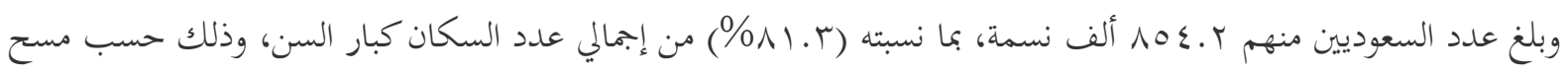

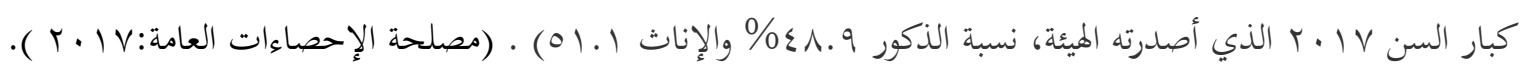

ومن هذه البيانات يتضح لنا أن المجتمع السعودي سيواجه مشكلة تزايد أعداد المسنين والمسنات كما تواجهها الدول المتقدمة في الوقت الحاضر، ويرى "العبيدي، . . ץ" أنه يجب أن يتوفر لهم جميع المتطلبات الطبية والاقتصادية والاجتماعية، بما فيها الأنشطة لشغل أوقات الفراغ، ويجب وضع المزيد من الخطط والإستراتجيات، ويقام العديد من الدراسات الميدانية والندوات العلمية للانتفاع والاستفادة من هذا المورث المعرفي الذي تراكم عبر السنين وتوظيفه في إعداد برامج وأنشطة تختص بالمسنين ( العبيدي، r. .r: (T/ ).

إن المسنات في البجتمع السعودي يحتجن إلى وسيلة للتنفيس والترويح يجددن من خلالها نشاطهن وحيويتهن وتعيد تأهيلهن للمجتمع، من خلال توفير بعض الأنشطة لقضاء وقت الفراغ الذي يقتحم حياهن، وخاصة بعد التقاعد عن العمل حيث تم اكتساب خبرات عبر سنوات أهدرت يصعب استرجاعها، فكثير من النساء مازال لديهن القدرة على أداء الأعمال بعد التقاعد .

يعد الفراغ من المسائل المهمة التي لا يمكن أن نقلل من أهميتها فهو مشكلة تحتاج إلى دراسة. إذ تشكل أوقات الفراغ التي يعاني منها الشباب والبالغين ·ع\% من أوقاقم اليومية، وترتفع عند المسنين إذ تصل إلى •V\% وخاصة بعد التقاعد عن

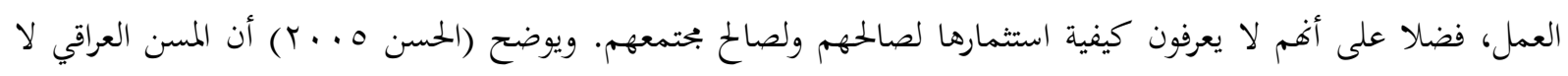
يفضل المشاركة في نشاطات الترويح لأنه لا يراها مهمة له، كما توصلت دراسة (خليفة ، . 199 1 إلى أن المسنين أقل الفئات

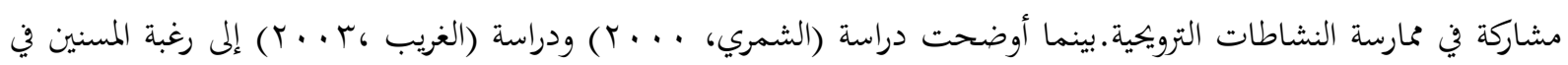


ممارسة أنشطة أو أدوار جديدة في حياتم إلا أها لم تحدد تلك النشاطات ونوعيتها و المعوقات التي منعتهم من المشاركة في النشاطات الترويحية لشغل وقت الفراغ، لذا من أسباب تناول هذا الموضوع الآتي: ا. الزيادة الملحوظة في أعداد المسنين بسبب التطور الصحي والثقافي والاقتصادي الذي تشهده المملكة العربية السعودية. r. أهمية ممارسة الرياضة في حياة المسنات إذ تعمل على تحسين الصحة النفسية والجسدية والعقلية. r. ضعف الاهتمام والتوعية بأهمية الرياضية للمسنات في المملكة مقارنة بالفئات العمرية الأخرى. ع. حاجة المسنات إلى نشاط رياضي لشغل وقت الفراغ وامدادهن بالطاقة والنشاط والصحة .

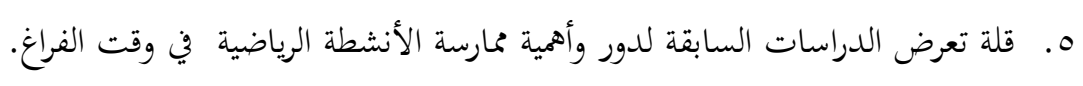
وفي هذه الدراسة تحديداً نحاول الكشف عن دور الأنشطة الرياضية في شغل أوقات فراغ المسنات.

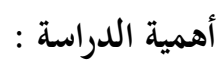

تتضح أهمية الدراسة الحالية في كوها تتناول فئة عمرية مهمة وحساسة هي النساء المسنات فمعظم الإحصاءات أشارت إلى أن نسبة المسنات السعوديات في تزايد ولا يمكن إغفالها أو تجاهلها، خاصة مع ارتفاع مستوى الوعي الصحي والرخاء الاقتصادي الذي تشهده المملكة، وماصاحبة من تحولات وتغيرات طرأت على كافة أبنية المختمع، وتحول الأسرة من متدة إلى الى نووية، وتقلص أدوار المسنات فيها فلم تعد الأسرة قادرة على توفير كافة احتياجاتن ومتطلباتن بما يتناسب مع هذا العصر، بما

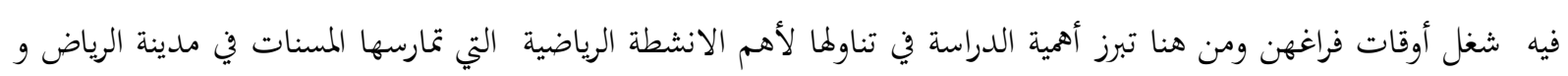
شغل أوقات فراغهن بالأنشطة المختلفة التي تعود عليهن وعلى مجتمعهن بالفائدة.

\section{الأهمية النظرية للدراسة:}

قد تسهم هذه الدراسة في توفير الإحصاءات والبيانات المبنية على أساس من البحث العلمي والدراسة الموضوعية حول دور الأنشطة الرياضية في شغل وقت الفراغ لدى المسنات، كما قد تساهم في إثراء العلم والمعرفة العلمية في تخصص علم اجتماع الشيخوخة، حيث أن معظم الدراسات والبحوث التي تناولت موضوع المسنين تناولته من جوانب مختلفة ومتعددة من مشكلات

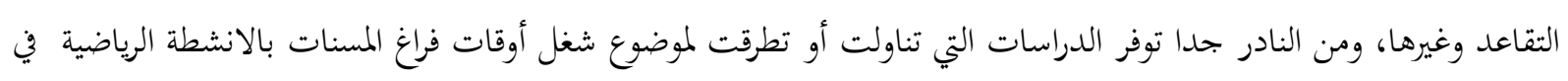
المملكة العربية السعودية، وخاصة في ظل ارتفاع توقعات أعداد المسنات في المجتمع السعودي.

1. - الأهمية النطبيقية للدراسة:

الاستفادة من النتائج والمقترحات التي توصلت لها هذه الدراسة والتي من الممكن أن تفيد المعنيين بهذا الأمر من المتخصصين الاجتماعين من الجمعيات الخيرية، أو مؤسسة التقاعد العامة، أو مؤسسة التأمينات الاجتماعية، أو وزارة الشؤون الاجتماعية وغيرهم ممن له علاقة بالمسنات. 
الهدف الوئيس : التعرف على دور الأنشطة الرياضية في شغل وقت الفراغ لدى المسنات في مدينة الرياض.

ومنه تستمد الأهداف التالية:

1. التعرف على الخصائص الاجتماعية والاقتصادية للمسنات المشتركات بمركز الأمير سلمان الاجتماعي. r. التعرف على كيفية قضاء المسنات بمركز الأمير سلمان الاجتماعي لوقت فراغهن. r. التعرف على أنواع الأنشطة الرياضية والترويحية تمارسها المسنات داخل مركز الأمير سلمان الاجتماعي. تساؤلات الدراسة : n n التساؤل الائيس:مادور الأنشطة الرياضية في شغل وقت الفراغ لدى المسنات؟

1. ما الخصائص الاجتماعية والاقتصادية لدى المسنات السعوديات المشتركات بمركز الأمير سلمان الاجتماعي ؟ r. كيف تقضي المسنات السعوديات المشتركات بمركز الأمير سلمان الاجتماعي وقت فراغهن؟ r. مأنواع الأنشطة الرياضية او الترويحية التي تمارسها المسنات السعوديات داخل مركز الأمير سلمان الاجتماعي؟ المفاهيم:

النشاط البدني الرياضي: يمثل المظاهر المختلفة الأشكال والمتعددة من النشاط الرياضي في مؤسسات التربية والتعليم وهو جزء من التربية وله ثلاث أشكال، منها درس التربية البدنية والنشاط الداخلي والنشاط الخارجي حيث يزود الفرد بخبرات واسعة ومهارات كثيرة تمكنه من التكيف مع بحتمعه وبتعله قادرا على أن يشكل حياته وتعينه على مسايرة العصر في تطوره ونموه.(تقي الدين:1)

\section{وتعرف دائرة معارف العلوم الاجتماعية الترويح:}

"بأنه النشاط الذي يقوم به الفرد في وقت الفراغ لذاته وليس لأي عملية كسب سواء كان هذا النشاط جسمانياً أم

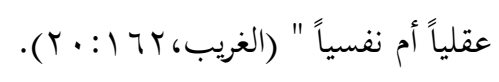

المفهوم الإجرائي للنشاط الرياضي في هذه الدراسة:

هو كل بحهود بدلن تمارسه المسنات السعوديات وذلك حسب إمكانيتهن الإقتصادية والإجتماعية و قدراتن الصحية والعقلية لشغل أوقات فراغهن بحيث يعيدلهن النشاط والحيوية . 
تعرف الكبر ( Aging ) بأنه تلك التغيرات الفسيولوجية المرتبطة بالتقدم بالسن كما يرتبط التقدم في السن بالمرض وهذا أمر طبيعي أن يحدث للفرد في دورة حياته لان المسنين أكثر الفئات العمرية عرضة للإصابة بهذه الأمراض المزمنة وفقدان العمل.

\section{المفهوم الإجرائي للمسن في هذه الدراسة:}

هي المرأة السعودية المسنة والتي بلغت عمر . ب سنه فأعلى تعيش في مدينة الرياض متعلمة كانت أو أمية يمكن أن تمارس بعض الأنشطة الترويحية في وقت الفراغ داخل وخارج المنزل . مركز الأمير سلمان الاجتماعي: - م

مؤسسة خيرية جاءت استجابة لحاجات ورغبة أبناء منطقة الرياض لوجود مؤسسة اجتماعية يقضون بها أوقات فراغهم وهي متنوعة الخدمات منها الاجتماعية والثقافية والرياضية والطبية والعلاجية وهي متاحة لجميع فئات المجتمع العمرية. 
يُعد تناول الطعام الصحي وممارسة النشاط البدني من أهم الأمور التي يمكن القيام بها للوقاية من أمراض القلب، وتحسين الحالة

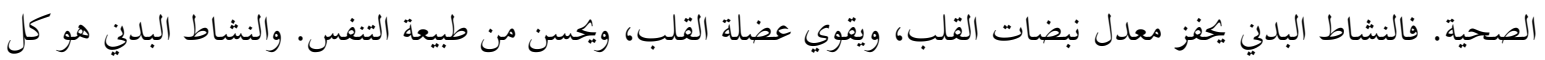

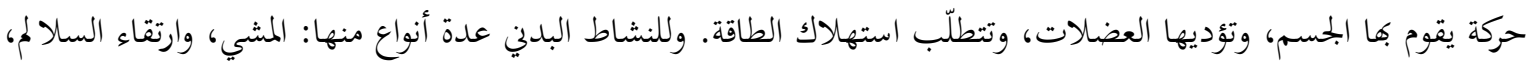

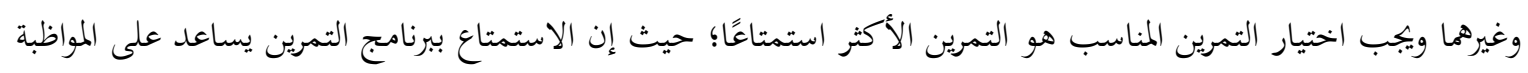

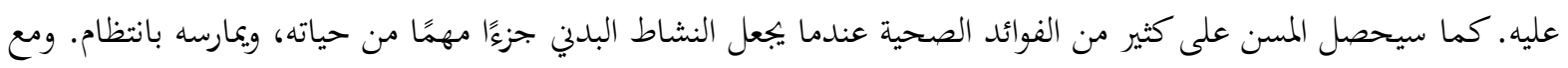

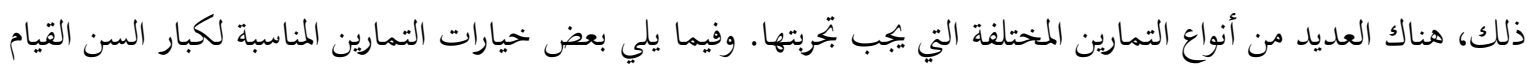

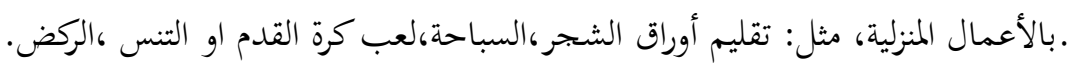

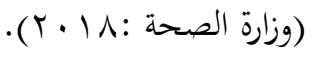

كما يدعو الإسلام إلى التجديد الدائم والتطوير في سلوك الأفراد بقصد إثرائه وإرتقائة، ويحرص على استغلال وقت الفراغ في كل ماهر مفيد، فالترويح في الإسلام أمر مباح طالما أنه في الإطار الشرعي المنضبط، ويعتبر الترويح في الإسلام وسيلة وليس غاية فهو وسيلة اجتماعية وتربوية بغرض تجديد نشاط الفرد وحيويته، وإشباع حاجاته البدنية، والنفسية، والعقلية، والروحية، فبعد العمل والكدح يأخذ المسلم قسطاً من الراحة والاستجمام، يريح بها جسده ويعيد النشاط لعقله، إذا يقول صلى الله عليه وسلم "روحوا القلوب ساعة وساعة" فقد كان الرسول عليه أفضل الصلاة والتسليم يحث أصحابه على التوازن بين حاجتهم الروحية، والبدنية، والاجتماعية ،وأن لايطغى جانب على آخر لذا قال الرسول صلى الله عليه وسلم لعبد الله " ياعبد الله ألم أخبرك أن تصوم النهار وتقوم الليل قلت:بلى يارسول الله قال :فلا تفعل صم وأفطر، وقم ونم فإن لجسدك عليك حق وأن لعينك عليك حقا وإن لزوجك عليك حقا"(موسوعة الحديث، ع ا · ب).

\section{1 أهمية الترويح بالنسبة للفرد}

للترويح أهميته الكبيرة في حياة الأفراد والمختمعات إذا يعمل على تحقيق الحاجات الإنسانية لتعبير عن الذات، وتحسين الصحة البدنية، والعقلية، والانفعالية للفرد، والتحرر من الضغوط والتوتر العصبي والقلق المصاحب للحياة العصرية، وكذلك تساعد بعض الأنشطة الترويحية على الترابط الأسري إذا أشترك فيها أفراد الأسرة، وتساعد الأنشطة الترويحية في تحديد الشخصية من خلال تنمية بعض المهارات والقدرات. 


\section{أهمية الترويح للمجتمع}

ويرى( الحماحي، 197 (1) أن الترويح مهم للمجتمع كما للفرد، فهو يساعد الفرد على الاتصال بالآخرين والتفاعل بينهم، وينمي روح الانتماء للجماعة، يمثل الترويح نظام الضبط الاجتماعي للأفراد المشاركين في نشاط معين، ويساهم التوويح في رفع الروح المعنوية والشعور بالأمان في البمتمعات وذلك بالتقليل من ارتكاب الجرائم والانحرافات، ويمكن معرفة حضارة شعب بأكمله من خلال معرفة الوسائل والأنشطة الترويحية التي يمارسها الأفراد، ويساعد الترويح في رفع عجلة التنمية البشرية من خلال معطياته الثقافية والاجتماعية.

\section{ثالثا: تصنيف الأنشطة الترويحية}

يوجد الكثير من البرامج والأنشطة الترويحية والتي تختلف في نوعيتها، كما لايوجد تصنيف واحد لهذه الأنشطة الترويحية التي يمارسها الإنسان في وقت الفراغ، فهنالك العديد من التصنيفات التي حاول مصنفوها أن تحتوي على جميع الأنشطة الترويحية الممارسة في وقت الفراغ، وفيما يلي عرض لأبرز تلك التصنيفات والتي طبقت بشكل خاص على المختمعات الإسلامية كالآتي: أولا :تصنيف " دورانت "كما وردت عند (السدحان، 1991 : Vr:) حيث صنف الأنشطة الترويحية التي تمارس في وقت الفراغ إلى أربعة أقسام رئيسية هي:

( ) أنشطة إبتكاريه: وهو نشاط ترويمي يمارسه الفرد في وقت فراغه، ويقوم على عمل ابتكارات وأفكار وممارسات غير مسبوقة مثل :الاختراعات.

r) أنشطة إيجابية: وهي الأنشطة التي تؤدي إلى نتائج مثمرة للفرد ولمجتمع كالنشاطات الرياضية، والرسم، والنحت . r) أنشطة عاطفية: وهي الأنشطة التي يتعامل معها الفرد بعاطفته مثل: سماع الأغاني والموسيقى. ع) أنشطة سلبية: وهي الأنشطة التي لا يكون فيها فائدة للفرد وللمجتمع ويكون دور الفرد فيها متلقي ومستقبل دون المشاركة فيها. ثانيا :تصنيف " عطيات الخطاب" كما أوردها (السدحان،991 199 \& ) حيث قامت بالعمل على تقسيم الأنشطة الترويجية التي يمارسها أفراد البمتمع في حياقم اليومية في أوقات الفراغ إلى أصناف رئيسية هي: 
أنشطة ثقافية: مثل القراءة والكتابة، والمراسلة للأصدقاء والصديقات، وحضور المحاضرات والندوات، والمناظرات، وحلقات البحث والمناقشة، وسماع الراديو، ومشاهدة التلفيزيون. أنشطة فنية: مثل الفنون التشكيلية، والرسم، والنسيج، وأعمال الصلصال، والنحت، وجمع الطوابع والعملات والصدف، والتصوير، والخط ،والتمثيل. الأنشطة الاجتماعية: مثل الحفلات التي يقيمها الأفراد في الأعياد، والحفلات التنكرية، وحفلات التخرج، والألعاب، والمهرجانات الاجتماعية، والغنائية، والفنية. الأنشطة الخلوية: مثل النزهات البرية والبحرية، والرحلات الخلوية والتجوال، وصيد الأسماك والحيوانات، والمعسكرات الكشفية. الأنشطة الرياضية: وهي جميع الأنشطة الرياضية بأنواعها وأقسامها سواء كان الإنسان يمارسها ممارسة فعلية أو يشاهدها فقط. رابعا : تصنف الأنشطة الرياضية : 1 - الأنشطة التي تعتمد على الطاقة الهوائية (الأكسجين) وهي تلك التمارين التي تتطلب بل وتعتمد على الأكسجين.

$$
\text { مثل - المشي. - السباحة. - الجري. }
$$

ץ- الأنشطة التي تعتمد على الطاقة اللاهوائية. وهي التمارين التي لاتعتمد على الاكسجين عند القيام بها مثل رفع الاثقال وتمارين الضغط.

ب- أنشطة المرونة والليونة. تمارين مد العضلات وبسطها والتي تزيد من ليونة الجسم ومرونته من مزاياها: - تقلل من نسب التعرض للإصابة. - ترفع من أداء الإنسان. - تزيد من نطاق حركة جسم الإنسان.(نادي السلام:V. . . T)

\section{خامسا:العوامل المؤدية إلى تباين الأنشطة الترويحية :}

تختلف الأنشطة الترويحية التي يمارسها الأفراد في أوقات فراغهم بإختلاف عدد من المتغيرات، كما أن دوافعها ومحفزاتما تختلف من فرد إلى آخر كما وردت عند (السدحان، 1991 ) (ودرويش، 1911) و و(خليفة، •99 19 ) وأبرز تلك العوامل الآتي: 
1) الجنس: تختلف الأنشطة الممارسة في أوقات الفراغ باختلاف الجنس، فالذكر له أنشطة ترويحية تناسبه كما للأنثى أنشطة ترويحية تناسبها، فالذكور يميلون إلى الأنشطة ذات الطابع البدني التنافسي، في حين تقبل الإناث على النشاطات الترويحية الهادئة التي تمارس غالبا في المنزل أو مع الصديقات.

r) العمر: يؤثر العمر في تحديد نوع النشاط الترويحي الذي يمارسه الأفراد، فالأطفال لهم أنشطتهم الخاصة وفي الغالب أغا ذات طابع حركي، في حين تكثر الأنشطة الثقافية والقراءة والرحلات بين كبار السن والبالغين، بينما تمتاز أنشطة فئة الشباب بالتنوع إلا أن الجانب الرياضي والرحلات البرية تطغى على الأنشطة الترويحية التي يمارسها الشباب. ץ) المستوى التعليمي: يتدخل المستوى التعليمي بشكل كبير في تحديد النشاط الترويحي الذي يمارسه الأفراد خلال وقت فراغهم، فالقراءة مثلا بجدها تكثر بين ذوي المستويات التعليمية المرتفعة ولا يمكن أن بحدها بين فئة الأميين أو الأطفال، كما يوجد علاقة طردية بين مستوى التعليمي وتخصيص جزء من الدخل للصرف على الأنشطة الترويحية وبخاصة ما كان من الأنشطة في بحال المهن والحرف. ع) الحالة الاجتماعية: تؤثر الحالة الاجتماعية على كمية وقت الفراغ، إذا أن الأفراد المتزوجين لديهم مسؤوليات، والتزامات أسرية بخلاف الأفراد غير المتزوجين.

ه) المستوى الاقتصادي للأفراد: ويؤثر هذا العامل من خلال القدرة على هيئة وتوفير الوسائل والأدوات التي من خلالها يمارس الفرد الأنشطة الترويحية، فالرحلات الخارجية والسفر والسياحة قد لا تتحقق لأصحاب الدخول المنخفضة.

\section{سادسا: الأننطة الترويحية التي يوفرها المجتمع السعودي:}

تعد جميع أوجه الرعاية المقدمة للمسنين في المجتمع السعودي نابعة من تعاليم الدين الإسلامي الحنيف، وتأخذ رعاية المسن وجوه عدة منها ما هو اقتصادي، واجتماعي،وصحي، ونفسي، وإيوائي، وتتمثل الرعاية الاقتصادية للمسن في ما يقدمه نظام التقاعد، ونظام التأمينات الاجتماعية، والضمان الاجتماعي فجميعها تعمل على توفير احتياجات المسن وأسرته المالية. وترى الباحثة أهمية الترويح للمسنات في المجتمع السعودي، وخاصة أن هناك أنواع مختلفة من الأنشطة الترويحية التي يوفرها البحتمع كالأنشطة الثقافية، والأنشطة الرياضية، والأنشطة الاجتماعية، والأنشطة العلاجية، وكل نوع من هذه الأنشطة يلبي احتياجات معينه لدى المسنات، بعضها يقدم داخل مركز الأمير سلمان الاجتماعي، وبعضها يقدم من قبل المؤسسات 
الأخرى،ولأهمية دور مركز الأمير سلمان الاجتماعي للدراسة الحالية سأتناول انجازاته في الآتي: (موقع مركز الأمير سلمان

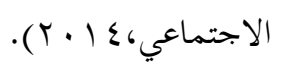

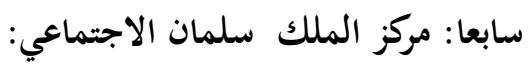

تم افتتاح المركز في الثاني عشر من شهر رمضان المبارك لعام (Vا乏 اهـ) على شرف صاحب السمو الملكي الأمير

سلطان بن عبدالعزيز رممه الله، ويعد المركز مؤسسة خدمية اجتماعية تقدم العديد من البرامج، والأنشطة الثقافية، والاجتماعية ،والترويحية ،لأفراد البتمع، كما يجرص المركز على المشاركة في المناسبات الوطنية، والأعياد، مع المؤسسات والجهات المختصة لدعم

$$
\text { البرامج المستهدفة. }
$$

ويقوم مركز الأمير سلمان الاجتماعي على بحموعة من الأهداف التي تعمل على تعزيز احترام الذات عند المسنين عن

$$
\text { طريق استعادة إحساسهم بذواقم ومساعدقم نفسياً واجتماعياً من خلال الآتي: }
$$

1. ب بيان أهمية بر الوالدين من الناحية الدينية، والدنيوية، والحث على ذلك وتوعية الناس.

r. بت تجنيب المسن الوحدة والاكتئاب من خلال اللقاءات، والنشاطات التي يعدها المركز.

r. تقديم الرعاية الطبية للمسنين و إتاحة الفرصة للمسنين بالإسهام والمشاركة بخبراتم ومعرفتهم للمركز .

ع. ـ حث المسنين على المشاركة والاندماج مع حياة الجماعة.

ه. تنمية القدرة لدى المسنين على التأقلم والتكيف مع التغيرات التي تحدث في الجتمع.

النشاطات الاجتماعية التي يقدمها مركز الملك سلمان الاجتماعي:

الأنشطة الصحية والطبية

في هذا القسم تتولى مدربات مختصات إعداد برامج وأنشطة في بحال الرياضة واللياقة البدنية والعلاج الطبيعي والتغذية ، كما

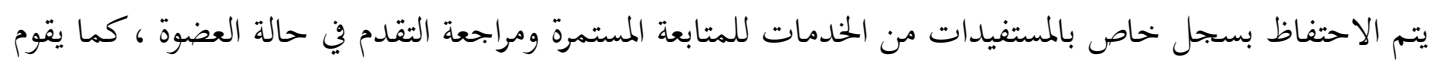
القسم بالكشف الدوري ومتابعة الحالة الصحية للعضوات وتقديم الاستشارات الطبية كما ينظم دورات في الإسعافات الأولية واللياقة البدنية .

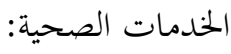

كالكشف الدوري للحالة الصحية للعضوات و برامج التوعية و الثثقيف الصحي و خدمات الإسعافات الطبية و التحليل و توفير نظام الحمية و التغذية السليمة.

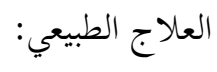

كالتمارين العلاجية المتنوعة و الكشف على الإصابات و الكدمات البسيطة و إجراء تمارين رياضية في المسبح بالإضافة إلى 


$$
\text { جلسات العلاج الطبيعي لبعض الحالات المرضية. }
$$

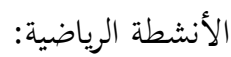

هناك العديد من الأنشطة الرياضية التي تمدف إلى الحفاظ على اللياقة الصحية كرياضة المشي و السباحة و التمارين

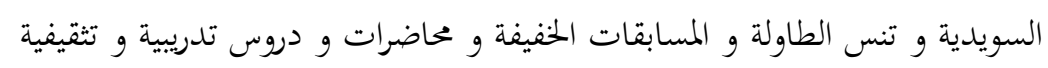

الأنشطة الاجتماعية:

كالبحوث الاجتماعية للفئات الخاصة،و الخدمات التنسيقية مع مكاتب الخدمة الاجتماعية في الأجهزة المختلفة و المشاركة في المناسبات الوطنية و الأيام العالمية، وإقامة الأسواق و الأسابيع الخيرية.تشجيع العمل التطوعي و تفعيل دوره بين العضوات، و و

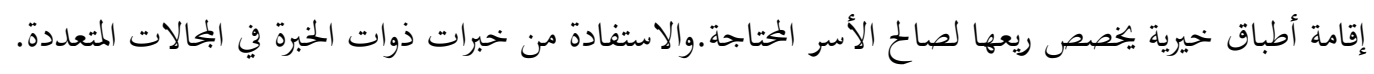

الأنشطة الثقافية:

مثل إقامة الندوات العلمية و الأدبية و الأمسيات الشعرية.وإقامة حلقات نقاش جماعي مع اختيار موضوع معين و دعوة مختصة •

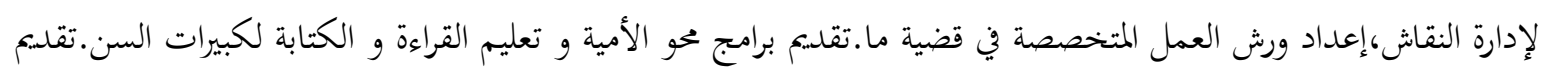

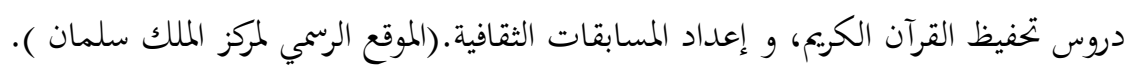
المبحث الثاني : المسنون

يتناول هذا المبحث مكانة المسنين في الإسلام، وأهم المشكلات المصاحبة لمرحلة الشيخوخة، وأهم التغيرات المصاحبة لمرحلة الشيخوخة مع عرض لنماذج من نشاطات المسنين.

\section{أولاً) مكانة المسنون في الشريعة الإسلامية:}

حرص الإسلام على تنظيم العلاقات الأسرية والاجتماعية على أساس من العدل، والمساواة، والتعاون والإخاء، فقد حرص على صون كرامة الإنسان في كل مراحل عمره، و عني عناية خاصة بتوقير الكبار، واحترامهم، والعطف عليهم والإحسان إليهم وخاصة الوالدين، لقوله تعالى "وقضى ربك إلا تعبدوا إلا إياه وبالوالدين إحسانا إما يبلغن عندك الكبر أحدهما أو كلاهما فلا تقل لمما أف ولا تنهرهما وقل لمما قولاً كريماً "سورة الإسراء آية ب).

حث الإسلام الإنسان على بر الوالدين والإحسان إليهما في كل مراحل العمر وضرورة رعايتهما خاصة عند الكبر، حيث يصبحون في حاجة ملحه وماسه للرعاية والعناية، وجعل سبحانه وتعالى الاهتمام بالوالدين بعد الأمر بعبادته لقول تعالى "اعبدوا الله ولا تشركوا به شيئا وبالوالدين إحسانا "(سورة النساء آية ب؟ب). 
تتعدد مظاهر رعاية كبار السن في المملكة العربية السعودية، وتأخذ أشكالا عدة فمنها ما يكون إقتصادياً من خحلال

الدعم المادي لكير السن، ومنها مايكون إجتماعيا تتمثل في دمج المسن في البمتمع، وسحبه من عزلته ووحدته، والرعاية الإيوائية لكبير السن، وهي تقدم للمسنين الذين لاعائل لهم وتنقسم إلى قسمين أثنين، الأول : رعاية حكومية في دور الرعاية الاجتماعية، والثاني : رعاية من خلال الدور الإيوائية الملحقة في الجمعيات الخيرية. وسنتناول بالحديث عن جميع مظاهر هذه الرعاية عبر المحاور التالية:

\section{أ- الرعاية الاقتصادية للمسنين في المملكة العربية السعودية:}

ويقدّم هذا النوع من الرعاية للمسنين في المملكة العربية السعودية عبر ثلاث أنظمة ظهرت في المملكة منذ سنوات طويلة وهي:نظام التقاعد، ونظام التأمينات، والضمان الاجتماعي.

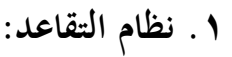

نشأ نظام التقاعد بسبب تزايد عدد الموظفين المدنيين والعسكريين في الدولة، وقد أدّى ذلك التزايد في عدد الموظفين إلى إيجاد نظام يخدم هذه الفئة من العاملين في الدولة بعد بلوغهم مرحلة متقدمة من العمر أو عجزهم عن العمل،ولقد صدر أول نظام للتقاعد في المملكة العربية السعودية عام ع ب ا هـ، وأسندت مهام تنفيذ هذا النظام إلى وزارة المالية، فأصدرت المملكة العربية السعودية عدد من الأنظمة الخاصة بالتقاعد، تحدف إلى حماية حقوق المتقاعدين والمستفيدين من أسرهم، ومنحهم مظلة تأمينية تحقق ما يصبون إليه من مستوى معيشي كريم ومستقر وتنظم حقوق المتقاعدين ·

\section{ب التظام التأمينات الاجتماعية.}

ويعد نظام التأمينات الاجتماعية صورة من صور التعاون والتكافل الاجتماعي التي يقدمها البحتمع لمواطنيه، ويقوم على رعاية العاملين في القطاع الخاص وكذلك العاملين على بند الأجور في القطاع الحكومي، ليوفر لهم و لأسرهم حياة كريمة بعد تركهم العمل بسبب التقاعد أو العجز أو الوفاة وكذلك العناية الطبية للمصابين بإصابات عمل أو أمراض مهنية و التعويضات اللازمة عند حدوث عجز مهني أو وفاة . 
لقد صدر نظام الضمان الاجتماعي ليكفل للمواطن السعودي المستحق لهذا النظام حداً أدنى من العيش يقيم به حياته

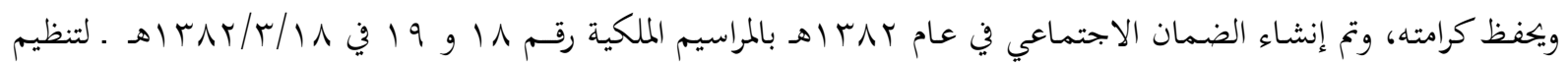
مساعدة الفئات الفقيرة و المحتاجة من الأسر والأفراد، ورعايتهم المستمرة ضد الحاجة و العوز وليكفل لهم حداً أدنى من العيش الكريم ويوفر لهم حياة كريمة ويرفع عنهم ذل المسألة ويحفظ كرامتهم · (المؤسسة العامة للتقاعد، ع ا • ؟)

\section{الرعاية الاجتماعية المفتوحة للمسنين في المملكة العربية السعودية .}

وهذا هو النوع الثاني من أنواع الرعاية التي تقدم للمسنين في المملكة العربية السعودية، بحيث تعمل على دمج المسنين في

المخيط الخارجي ومشاركتهم فيهم وذلك ليستعيدوا ثقتهم في أنفسهم، ويمثل هذا النوع من الرعاية: مركز الأمير سلمان الاجتماعي بمدينة الرياض وسبق الإشارة إليه في الفصل الثاني من هذا البحث.

\section{ج- الرعاية الإيوائية الشاملة للمسنين في المملكة العربية السعودية.}

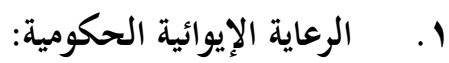

لقد بدأت الرعاية الإيوائية من قبل الدولة للمسنِّن في المملكة العربية السعودية، أو مـا يعرف بالرعاية المؤسسية في عام ـ هـ اهـه،وتمدف دور الرعاية الاجتماعية إلى إيواء وتقـديم أوجـه الرعاية لكل مـواطن ذكرأكـان أم أنثى إذا بلغ سـ الستين فأكثر،ويكون عاجزاً عن العمل أو القيام بشؤونه الشخصية بنفسه، ولا يتوفر لدى أسرته أو أقاربه الاستعداد أو الإمكانيات لرعايته، بالإضافة إلى أنّ الدور تقدم الرعاية للمرضى المسنِين الذين لا عائل لهم.

\section{ب الرعاية الإيوائية الأهلية : ب الرية}

قامت وزارة الشئون الاجتماعية منذ نشأقما بتنشيط المبادرات الفردية والجماعية في العمل الاجتماعي، ودفع الناس إلى تنظيم الأعمـال الخيريـة التي يقـدموفها مـن خـلال الجمعيـات الخيريـة فقامـت بوضـع نظـام الجمعيـات والمؤسسـات الاجتماعيـة الأهلية عام (ع ^ ا اهـ) والذي ينظم العمل التطوعي والجهود الأهلية الفردية والجماعية من خلال إنشاء بحالس للجمعيات الخيرية وضبط الأمور المالية والإدارية بما. 
يصاحب مرحلة الشيخوخة بعض من التغيرات الجمسمية، والنفسية، والصحية، وبعض المشكلات الاجتماعية، والصحية،

والمالية وسوف نوضحها في الآتي:

\section{: (1) ( ) التغيرات الجسمية}

تتعرض معظم أجهزة الجمسم ووظائفها للتغير الواضح، والقصور مع التقدم في العمر وتفقد كفاءها وتكون خارجية يمكن رؤيتها وداخلية، وتبدأ أولها في الجلد الذي يكون عادة خشن وفاقد اللمعان والنعومة، وتظهر فيه التجاعيد والتصبغات، وانتشار الشيب في الشعر وتراجع في نشاط الحواس وخاصة السمع والبصر، كذلك ضعف القوة الانقباضية وتراجع ردود الأفعال، أما من النواحي الداخلية يتعرض المسن لفقدان مرونة الأوعية مما يزيد احتمال إصابته بتصلب الشرايين، وعدم القدرة على التنفس، وقد تتعرض العظام للكسور، وفقدان المناعة وبطء عمليات النمو والبناء (رياض: • + † )

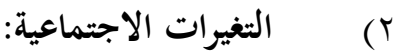

تضعف في مرحلة الشيخوخة العلاقات الاجتماعية بين المسن ومعارفه، ويزداد هذا الانكماش حتى تصبح دائرة نشاطه قاصرة على العلاقات الأسرية فقط، لذا يبدأ المسن بالانسحاب والعزلة من واقع الحياة الأسرية والمختمعية وخاصة بعد زواج الأبناء واستقلالهم، وموت الرفقاء والأصدقاء. وتعاني النساء من الوحدة أكثر من

$$
\text { الرجال باعتبار أن العمر يمتد بهن أكثر(السيد:9V0 ( ) ). }
$$

\section{ب) التغيرات النفسية:}

من أهم التغيرات النفسية التي تعتري المسنين في هذه المرحلة الغضب لأتفه الأسباب وهذا ناتج من إحساسه بعدم اهتمام الآخرين به، كما تعتيهم الأنانية والتمركز حول الذات ولفت الانتباه، ويزيد حرص المسن على ممتلكاته خوفاً من المستقبل وغالباً مايرفض مساعدة الآخرين، وبحد كذلك العناد والتشبث بالرأي حتى وإن كان موقفه خطأ ولكنه يحاول أن يثبت للآخرين أنه مازال له موقف ورأي، ونلاحظ إهمال المسنين أو المسنات لمظهرهم وعدم الاهتمام به وهذا تعبير عن الانسحاب من الحياة وعدم الاكتراث بها، وكما تعتريهم صفة الشك بالآخرين وعدم الثقة بهم، والنفور من الغرباء مع الإحساس المتزايد بالوحدة نتيجة عدم مشاركتهم في الأنشطة التي تشغل وقت الفراغ(رياض: • • • ( ). 
يتعرض المسنين إلى بحموعة من التغيرات العقلية المتفاوتة في درجتها وتأثيرها، وأن كثيرا من هذه التغيرات ترجع قبل كل شئ إلى ماقد يصيب المخ من ضمور وتلف بسبب الكبر، أو بسبب ماتعرض له خلال حياته من مواقف، أو صدمات عاطفية، أو إنغعالية ظهرت آثارها عليه، ومنها النسيان سواء نسيان بعض المواقف، أو الأحداث، وعدم القدرة على التعلم بسهوله (عبد

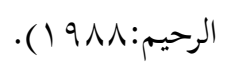

\section{( ) م التغيرات الصحية:}

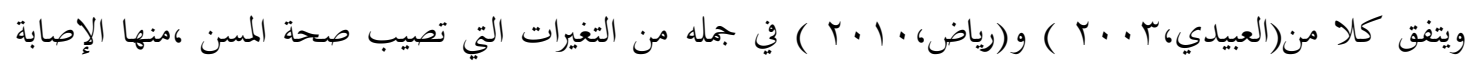
بمرض السكري، وكثرة الإجهاد والتعب، ونقصان الوزن، وهشاشة العظام، وسقوط الأسنان، والآم المفاصل،كثره الإصابات بالحلطات، والسكتات الدماغية، ومشاكل في القلب والأوعية الدموية، كما ترتفع نسبة الإصابة بالإمراض الخبيثة عند المسنين.

\section{ج) المشكلات المصاحبة لمرحلة الشيخوخة.}

$$
\text { فيما يلي عرض لبعض المشكلات التي قد يعاني منها المسنين . }
$$

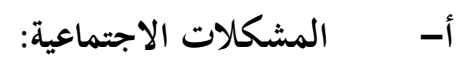

إن الشعور بالانتماء مهم جداً في حياة الإنسان، ولأن الإنسان كائن اجتماعي بطبعه لايستطيع العيش بمعزل عن الآخرين، فهو يحتاج إلى الدخول في تفاعلات، وعلاقات اجتماعية مع الآخرين، وكلما كبر الفرد مال إلى فقدان الشعور بالانتماء، وخاصة بعد التقاعد عن العمل، وانخسار العلاقات الاجتماعية وفقدان الجزء الأكبر منها بسبب الوفاة، أو الانقطاع

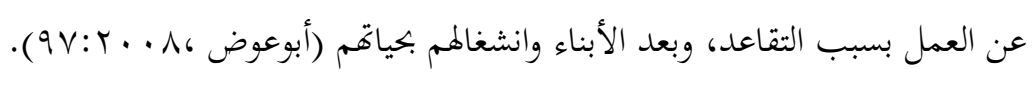
ب - مشكلة أتساع وقت الفراغ:

يزيد الإحساس بمشكلة وقت الفراغ بعد التقاعد عن العمل، حيث يجد الإنسان نفسه متحرراً وحراً من أي عمل، وتزيد حدقا مع عدم توفر المؤسسات الاجتماعية الخاصة بالمسنين، كما أن النظرة غير الإيجابية للمسنين من بعض فئات المختمع حيث

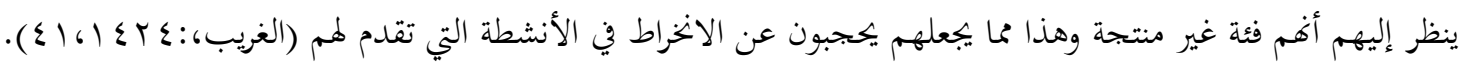


يعد الترمل من أهم المشكلات المرتبطة بالشيخوخة، حيث وفاة أحد الزوجين وترك الأخر وحيداً في مرحلة حرجه لها انعكاسات سلبيه من الحزن، والإحباط، والاكتئاب، وبخد أن الإناث يعانون من هذه المشكلة بشكل أكبر، ففي المملكة بند أن نسبه الترمل بين المسنين الذكور( (ب\%\%)، بينما هي (ץع\%) بين المسنات، لأن الذكور عادة مايتزوجون بعد وفاة زوجاتم

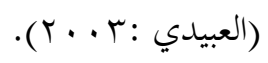

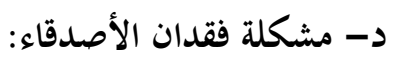

في مرحلة الشيخوخة ترتفع معدلات الوفيات ويعاني منها من يبقون من المسنين على قيد الحياة، ففقدان الأصدقاء والأقباء أو أحد الزوجين يمثل أزمة نفسية، واجتماعية وخاصة أن الأصدقاء يمثلون للمسن أحد مصادر الدعم الاجتماعي، ومصدر للعلاقات الاجتماعية، وتمضية الوقت، لأن فقدان الأصدقاء في مرحلة الشيخوخة تختلف عن مرحلة الشباب، لأن في الشيخوخة من الصعوبة أن يتم تعويض الأصدقاء أو الانخراط في صداقات جديدة.

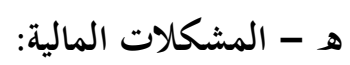

يعاني معظم المسنين في العالم من مشكلات مالية ترجع إلى التقاعد عن العمل وانخفاض الدخل، ويجمع كلا من

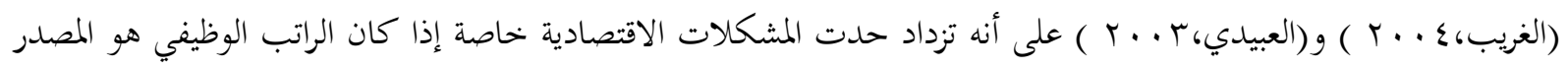
الوحيد للإنفاق على الأسرة، هنا يواجه المسن أزمة انخفاض دخله ومتطلبات أسرته في ظل غلاء المعيشة وارتفاع الأسعار.

النظريات الاجتماعية المستخدمة في الدراسة:

وسنعرض فيما يلي أهم النظريات الاجتماعية في بحال الشيخوخة ومناقشة دورها في الأبحاث الاجتماعية في هذا البمال.

نظرية الدور (Role Theory)

تنتمي هذه النظرية إلى المدرسة البنائية الوظيفية لعلم الاجتماع، حيث ظهرت في مطلع القرن العشرين وهي من النظريات الحديثة في علم الاجتماع، وتعتقد بأن سلوك الفرد وعلاقاته الاجتماعية إنما تعتمد على الدور أو الأدوار الاجتماعية التي يشغلها في المُتمع، وإن هذا الدور الاجتماعي ينطوي على واجبات وحقوق، علماً بأن الفرد لايشغل دوراً اجتماعياً واحداً بل 
يشغل عدة أدوار تقع في مؤسسات مختلفة وهذه الأدوار لاتكون متساوية في المؤسسة وحدها بل تكون مختلفة، فالدور حلقة وصل بين الفرد والبحتمع (الحسن، ه . ب ب: 109 1). وتستند نظرية الدور على عدد من المبادئ العامة منها: ا. ـ يتحلل البناء الاجتماعي إلى عدد من المؤسسات الاجتماعية وتحلل المؤسسة الاجتماعية الواحدة إلى عدد من الأدوار الاجتماعية. r. ينطوي على الدور الاجتماعي الواحد بحموعة واجبات يؤديها الفرد بناء على مؤهلاته وخبراته وبحاربه وبعد أداء الفرد لواجباته يجصل على بجموعة حقوق . r. يشغل الفرد الواحد في البمتمع عدة ادوار اجتماعية وظيفية هي التي تحدد منزلته ومكانته الاجتماعية. ع. تكون الأدوار الاجتماعية متصارعة أو متناقضة عندما لاتؤدي المؤسسة مهامها بصوره جيده وإيجابية

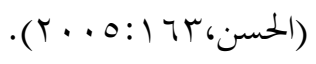

\section{النعليق على النظرية:}

ترى الباحثة أن المسنات لهن أدوار متعددة داخل الأسرة وخارجها وفهمهن لأدوارهن بالشكل الصحيح وتأديتهن لها يمكنهن من تحقيق التوازن، حيث يتساوى الأداء الفعلي للأدوار مع الأداء المتوقع. وفي المجتمع السعودي تتمتع المرأة بدور كبير داخل الأسرة ومكانة عالية، وتشغل العديد من المراكز الاجتماعية وكل مركز مرتبط بأدوار خاصة به، وبحد الدور يتأثر بدرجة تعليم المرأة وثقافة الجماعة، إذا أها زوجة وأم تقوم بعملية التنشئة الاجتماعية، والتوجيه والإرشاد، وامرأة عاملة، ومع تقدمها بالعمر ووصولها لمرحلة التقاعد تغيرت أدوارها وفقدت العديد منها والتي كانت تؤديها سابقا، ويجب عليها إيجاد بدائل للأداور التي فقدها لتتوافق مع وضعها في المختمع ولتنعم بشيخوخة مثلى، كما أن لكل دور توقعات معينة من الناس الآخرين، وإذا فشلت المسنة في أداء دورها وتنازلت عنه فإن المتمع يتناساها لضعف دورها وقد تصبح عالة على أفراد أسرقا.

نظرية النشاط:

تعد نظرية النشاط من أقدم النظريات في بحال علم الشيخوخة الاجتماعي منذ أن قدمها (روبرت هارفستR.Havighurst) في عام rابه ام. لقد كان لنظرية النشاط دور بارز في توجيه الأبحاث في بحال الشيخوخة 
الاجتماعي، والاهتمام بمفهوم النشاط في مرحلة الشيخوخة، حيث تعددت الأبحاث التي جعلت من مفهوم النشاط محور اهتمامها، وتركز هذه النظرية على أهمية النشاط الاجتماعي في حياة الفرد، وترى أن النشاط الاجتماعي هو أساس الحياة لجميع الأفراد وفي مختلف الأعمار، وتفترض هذه النظرية أنه باستثناء التغيرات البيولوجية والمشكلات الصحية، فإن كبار السن والكهول يشتركون في حاجات نفسية، واجتماعية متماثلة، والشيخوخة المثلى عند أنصار هذه النظرية هي في الإبقاء على النشاطات المختلفة، ومقاومة تقلص الارتباطات الاجتماعية، والبحث عن بدائل للأدوات والنشاطات، وجميع ما يمكن أن يفقده الفرد من جراء التقاعد، أو فقدان من يرتبط بهم كالزوجة، أو الزوج أو الأصدقاء وغير ذلك، فمن هذا المنظور فإن كبار السن القادرين على الاحتفاظ بنشاطاتم الاجتماعية هم أكثر إيجابية نحو أنفسهم وأكثر ارتباطاً بمجتمعهم ورضا عن حياتم، ولقد ركزت الدراسات التي أخذت من نظرية النشاط محوراً لها على علاقة النشاط في مرحلة الشيخوخة بالرضا المعيشي، والعلاقات الأسرية، والتفاعل الاجتماعي، والتكيف لمرحلة التقاعد، وقد أدى الاهتمام بنظرية النشاط بصفتها أول نظرية في علم اجتماع الشيخوخة إلى تطوير وإدخال مفاهيم جديدة في حقل الشيخوخة الاجتماعية، ترتبط ارتباطاً وثيقاً بمفهوم النشاط حيث توجه الاهتمام إلى

$$
\text { دراسة مفاهيم جديدة مثل الأدوار وتعويض الأدوار وتحول الأدوار(العبيدي، ب. . ب: الج ). }
$$

\section{التعليق على النظرية:}

ترى النظرية أن رضا الممنات يتوقف على مدى إندماجهن في الأسرة والمجتمع، والإسهامات التي يضيفنها، وعلى إحساسهن بأهن مازلن نافعات ومطلوبات، فقيام المسنات ببعض الأنشطة يعد أمراً ضرورياً لزيادة رضاهن عن الحياة وقناعتهن بها، وربطهن بالمتمع وأفراده وتواصلهن مع المسنات الأخريات اللاتي يقاربنهن بالعمر، وكذلك مدى قدرتن على الاحتفاظ بالصداقات والعلاقات الاجتماعية، لأها هي التي بتلب لهن الاستقرار النفسي وبتعلهن يشعرن بالرضا والسعادة .

النظرية الاستمرارية:

وعلى نمط نظرية النشاط تأتي النظرية الاستمرارية لتؤكد أهمية النشاط من ناحية، وتضيف أهمية الاستقرار النسبي للأدوار التي أعتاد عليها الفرد في السابق من ناحية أخرى، وتفترض هذه النظرية أن الشيخوخة الناجحة هي التي تتصف بالقدرة على المحافظة والاستمرار على الأدوار، والنشاطات، والعلاقات في مرحلة التقاعد، فتكيف كبار السن، يتوقف على زيادة الوقت في مزاولة الأدوار والنشاطات التي كانوا يزاولوها قبل التقاعد ، عوضاً عن البحث عن أدوار جديدة، وتستند هذه النظرية على نتائج الدراسات التي تؤكد أن كبار السن يحاولون التشبث بالطرق التي جربوها عوضاً عن محاولة اتخاذ وسائل جديدة لم يكن لهم بها 
خبرة سابقة، كما يحاول معظم المتقاعدين أن يجعلوا حياقم بعد التقاعد مشاجة إلى حد كبير لحياقم قبل التقاعد

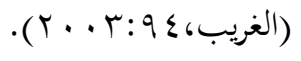

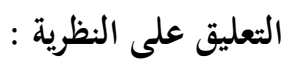

ترى هذه النظرية أن التكيف مع مرحلة الشيخوخة يعتمد على الحياة الماضية للمسنات، وقدرتن على الاستمرار في

الحفاظ على الأدوار والنشاطات والعلاقات السابقة، فإذا كانت لديهن ارتباطات وعلاقات اجتماعية مع الأقرباء، والصديقات، والجيران وحتى أبنائهن وأحفادهن، ولديهن نشاطات يمارسنها في وقت الفراغ سواء في المنزل أو خارجه يكن سعيدات، وكذلك لابد من الاستمرار في مزاولة الأنشطة وهذا يكون بوجود تشجيع ودعم من قبل الأسرة، أو أزواجهن أو أبنائهن لتخطي هذه المرحلة والتكيف معها.

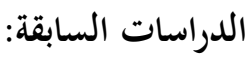

تعد الدراسات السابقة مهمة للباحث، حيث تساعده على بلورة مشكلة البحث، وتزويده بالأفكار والمفاهيم والنظريات المفسرة لموضوع بحثه، و لقد تعددت وتنوعت الدراسات التي تناولت موضوع المسنين من مختلف الجوانب سواء مشكلاتمم، أو احتياجاقهم، أو برامج الرعاية المقدمة لهم، من هذه الدراسات ماله علاقة مباشرة بموضوع الدراسة.

أولا:الدراسات المحلية

() دراسة إبراهيم خليفة وإدريس الحسن (• (99 ) بعنوان "الترويح في المجتمع العبي السعودي " دراسة

استطلاعية .

إن الهدف من إجراء هذه الدراسة هو التعرف على طبيعة الترويح في المجتمع السعودي بأنماطه الثلاث بدو، ريف، حضر، في مدينة الرياض وضواحيها وتم استخدام أداة الاستبيان والمقابلة على عينة عشوائية منتظمة بلغت (.00) ذكور وإناث من السعوديين ومن أعمار مختلفة وقد خلصت الدراسة بالنتائج التالية:

أتضح من نتائج التحليل أن نسبة ممارسي الألعاب والأنشطة التقليدية في الحضر مرتفعة ، وتقل عند الريفيين، والبدو فهم يتجهون إلى مستحدثات الترويح. كما استتتج أن للعمر علاقة واضحة بنوع النشاط الترويمي الذي يمارسه الفرد، وأن الفئات الأصغر عمراً تميل إلى الترويح خارج المنزل بالوسائل الأكثر عصرية وحداثة، وأن الذين يسافرون داخل المملكة وخارجها تقع 
أعمارهم بين هץ-هـ وأن الشباب السعودي أكثر ميلاً للسفر خارج المملكة من داخلها ، وأن غالبية من يفضلون الترويح مع الرفاق هم دون الخامسة والثلاثين ، بينما كبار السن لايميلون إلى الترويح مع الرفاق.

دراسة موضي الشمري ( . . . P أثر العوامل الاجتماعية والاقتصادية والصحية في بعض النشاطات المختلفة لكبار

السن "دراسة ميدانية في مدينة الرياض .

هدفت الدراسة إلى التعرف على بعض الأنشطة لدى كبار السن والعوامل المؤثرة على تلك النشاطات من عوامل اجتماعية، واقتصادية، وصحية، ومعرفة مدى استمرارهم على أنشطتهم السابقة أو إحلالهم أنشطة جديدة تلبي احتياجاقم المتعددة من مادية، ومعنوية، حتى يتوافقوا مع هذه التغيرات العمرية، واعتمدت الدراسة على منهج المسح الاجتماعي عن طريق العينة الغرضية وكان عددهم (Yll) مسن من مدينة الرياض ممن تنطبق عليهم محددات الدراسة، وتم استخدام أداة الاستبيان بتطبيقها على المبحوثين عن طريق المقابلة بمساعدة بجموعة من الباحثين لمعرفة اثر العوامل الاجتماعية والاقتصادية والصحية على بعض نشاطات كبار السن وخلصت الدراسة إلى النتائج الآتية:أن الفروق بين الفئات العمرية المختلفة وممارسة الأنشطة فروق جوهرية ذات دلالة إحصائية عند مستوى معنوية ( . , . ) كما تدل قيمة معامل حاما ع ع, ·) وأها علاقة متوسطة القوة، كما استنتجت أن الفروق بين من يعانون من الأمراض من ناحية والذين لايعانون من الأمراض في ممارسة الأنشطة الرياضية فروق بسيطة جداً وليست ذات دلالة إحصائية عند مستوى معنوية ( . , · ) واستنتجت أن الحالة الصحية ليست لها علاقة في ممارسة الأنشطة الرياضية.

دراسة عبدالعزيز الغريب (9 + + ץ) التفضيل الترويحي لكبار السن في مدينة الرياض.

تمدف الدراسة بشكل رئيسي للتعرف على التفضيل الترويمي لكبار السن، واعتمدت الدراسة على منهج المسح الاجتماعي بأسلوب الحصر الشامل وتم اختيار عينة من المسنين (YTV) واستخدم الباحث الاستبيان والمقابلات المتكررة وخلصت الدراسة إلى النتائج الآتية: - 20 - n

توصل الباحث إلى أن ممارسي النشاط الترويهي من كبار السن من عمر ـ ج-07 من يحملون المؤهل الجامعي وهم من

المتقاعدين وأوضاعهم الاقتصادية متوسطة، وكما توصل إلى أن أكثر من نصف العينة لديهم أراء ايجابية نحو الترويح، و أن الأنشطة الترويحية التي يفضلها كبار السن هي حفلات السمر، وافتتاح مشروع ، وممارسة الأنشطة الرياضية. 


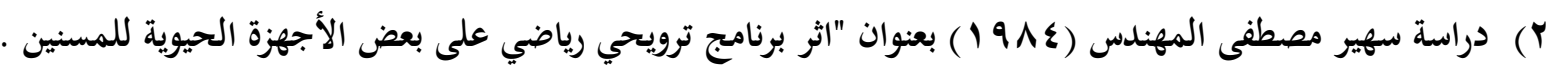
طبقت الباحثة دراستها على عينه قوامها (•V رجل مسن) بمنطقة مصر الجديدة بالقاهرة بالطريقة العشوائية، واستخدمت المقابلة الشخصية والاستبيان وتوصلت إلى النتائج الآتية:

أن استخدام البرنامج الترويحي الرياضي أدى إلى إنخفاض في معدل سرعه النبض، وضغط الدم وهذا يدل على تحسين الجهاز الدوري نتيجة ممارسه البرنامج الترويحي، وأن استخدام البرنامج الترويحي الرياضي أدى زيادة قوة عضلات الظهر وعضلات الرجلين، وأدى إلى تحسين التوافق العضلي والعصبي.

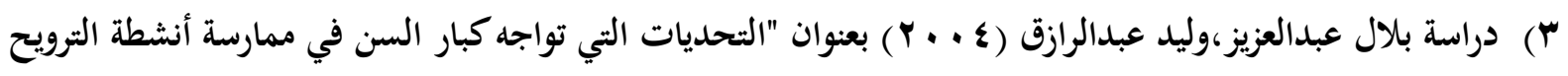
الرياضي بالأندية.

استخدام الباحثان المنهج الوصفي لملائمته لطبيعة الدراسة وأهدافها، وتمثلت أداة جمع البيانات في الاستبيان الذي صممه الباحثان وبلغ حجم العينة (VV) مفردة تم اختيارهم بالطريقة العمدية من كبار السن بنادي الصيد المصري ومن المشتركين بالأنشطة الرياضية وبينت نتائج هذه الدراسة أثر أنشطة الترويح الرياضي على الراحة والإسترخاء والسعادة كما وجدت أن التحديات التي تواجه كبار السن في ممارسة أنشطة الترويح الرياضي، هي عدم توفر الإمكانيات وأن الأنشطة لا تناسب ميول اهتمامات واحتياجات كبار السن.

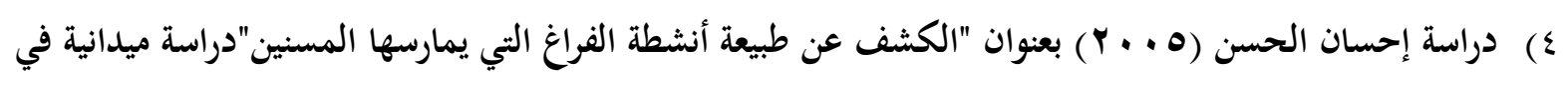
العراق.

اعتمد الباحث على أسلوب المسح الحقلي وكان هدف الدراسة توضيح ابحاهات (· .ع) مسن ومسنة بتحاه ماهية ونوعية النشاطات الترويحية التي يحتاجوها للترفية عن أنفسهم، واستخدم أداة الاستبيان لتحقيق هدف الدراسة وتساؤلاتما وكانت العينة من النوع المنتظم من بعض المناطق السكنية في العراق، مراعي التقسيم الحضري، والريفي، ومسألة التوزيع الجنسي ذكور وإناث ، وكانت الأعمار تتراوح مابين ه7 إلى · V فأكثر وخلصت الدراسة إلى النتائج الآتية: 
أن معظم المسنين يقضون وقت الفراغ في مزاولة أنشطة غير مفيدة حيث أوضحت الدراسة أن \% \% من الذكور

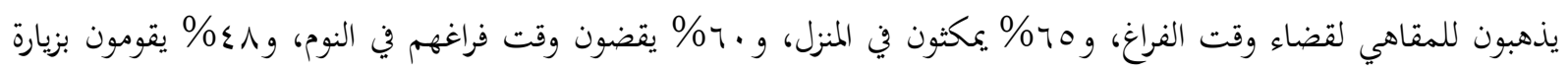
الأهل والأصدقاء، بينما بند أن rع\% يقضون فراغهم في سماع الراديو ومشاهدة التلفزيون، و9\% فقط يذهبون للنوادي والجمعيات ،بينما وجد أن ار٪\% من المسنات يقضين وقت الفراغ في المكوث في البيت، و • \%\% يقضين وقت الفراغ في الطبخ وإدارة شؤون المنزل، ،بينما بند با \%\% من المسنات يقضين وقت الفراغ في الذهاب إلى النوادي والجمعيات.

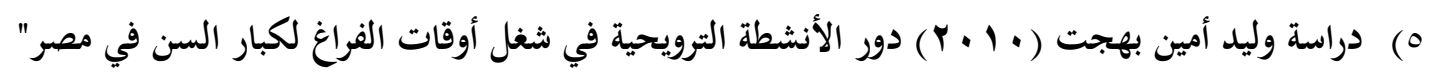
تعرف الباحث على حجم وقت فراغ كبار السن ودور الأنشطة الترويحية في الاستثمار الأمثل لوقت الفراغ، وقد استخدم الباحث المنهج التجريبي لمناسبته لطبيعة دراسته وأهدافه و إستخدم كذلك أسلوب القياس القبلي والبعدي على بحموعة واحدة متجانسة، و تم اختيار عينه البحث بالطريقة العمدية لغير ممارسي الأنشطة الرياضية بمحافظة الجيزة والذين وصلوا لسن التقاعد ولا يمارسون أي نشاط ترويحي، وتم استخدام أداة الاستبيان للحصول على المعلومات وخلصت الدراسة إلى النتائج الآتية: أدى تطبيق البرنامج الترويحي إلى زيادة الدافعية للممارسة الأنشطة الترويحية الرياضية بصورة مستمرة، وكذلك زادت مشاركة الأفراد في البرامج التويحية الرياضية مما زاد تنمية الشعور بالسعادة وتقليل الشعور بالتوتر، والقلق ، والضيق، والاكتئاب عند ممارسة الأنشطة الرياضية، وتساعد ممارسة الأنشطة الترويحية الرياضية على تقليل الإصابة بالاكتئاب والتوتر .

دراسة ثناء عبدالباقي وعليه خير الله (د.ت)"بعنوان دراسة مقارنه للبرنامج الترويحي في كل من دار المسنين في محافظة الغربية ومحافظة القاهرة لوضع برنامج ترويحي مقترح · تمدف الدراسة إلى وضع برنامج ترويمي مقترح يتناسب مع الأنشطة الترويمية التي يحتاجها المسنين من الجنسين في دور

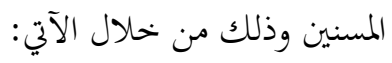

التعرف على الأغراض التي يحققها البرنامج الترويجي المنفذ لكلا من الجنسيين في دور المسنين في محافظة الغربية ومحافظة القاهرة، والتعرف على الأنشطة التي يحققها هذا البرنامج الترويحي والقيام بعقد مقارنه بين كلا من دور المسنين في محافظة الغربية ومحافظة القاهرة، للتعرف على الأغراض المشتركة التي يمققها البرنامج الترويمي المنفذ لكلا من الداريين، وكذلك الأنشطة المشتركة التي يحققها البرنامج الترويجي في كلا من الداريين. 
واستخدمتا المنهج الوصفي وأداة الاستبيان، وكذلك المقابلة الشخصية في كلا من الداريين بعينه عشوائية (0 ( مفرده من الذكور والإناث واستنتجت الباحثتان الآتي:

تشير أراء الغالبية العظمى من الحبراء في بحال الترويح على ضرورة توفر البرامج الترويحية التي تضم العديد من الأنشطة

المتنوعة لكلا الجنسين، وأتفق الغالبية العظمى من المسئولين بالدار على أن البرامج الترويحية من خلال أنشطة الخلاء عن طريق الرحلات، تسعى لتحقيق أغراضها خصوصاً أن المسنين من الجنسيين يفضلون الاشتراك فيها ،لأها بتمع مابين الأنشطة الثقافية ، والدينية والاجتماعية.

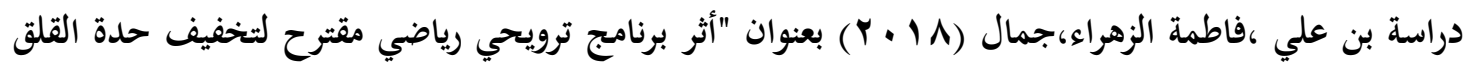
عند كبار السن " الجزائر.

وتمدف هذه الدراسة من خحلال نتائج الإختبارات الإستطلاعية و بعد المعالجة الإحصائية تم إختيار ـ ؟بفردا الذين يمثلون عينة الدراسة الأساسية حيث قسمت إلى بحموعتين (· با فردا يمثلون العينة التجريبية التي يطبق عليه البرنامج التوويحي و الثانية مكونة من • r ا فردا يمثلون البحموعة الضابطة التي لا تمارس أي نشاط رياضي حيث استخدم الباحثين المنهج التجريبي باستخدام التصميم التجريبي بلمموعتين إحداهما بجريبية والأخرى ضابطة متبعا القياس القبلي و البعدي لملائمته طبيعة هذه الدراسة. نتائج الدراسة:

) الفرضية الأولى تأكدت من خلال النتائج المتحصل عليها والموضحة في الجحدول رقم (V (حيث أن الفروق الإحصائية كانت معنوية في الإختبارات البعدية لصالح البمموعة التجريبية (الممارسة للنشاط الترويمي الرياضي) مقارنة مع العينة الضابطة (غير ممارسة) الشيء الذي يبرهن أن البرنامج الرياضي الترويجي المقترح أثر بشكل إيجابي على العينة التجريبية ، و عمل على خفض مستوى القلق عند فئة المسنين الممارسين للنشاط الرياضي الترويهي ) 2الفرضية الثانية ـ النتائج المتحصل عليها تطابقت مع الفرضية الثانية حيث أن النشاط الرياضي الترويحي له أهمية كبيرة في المحافظة على النفسي و البدني للمسن الممارس للنشاط الرياضي ، هذا ما لاحظناه من خلال تحلي ل مقاطع صور الفيديو التي التقطناها خلال الحصص حيث أظهرت أن الإحتكاك المستمر مع الجماعة من خلال اللعب و التنافس يبعث نوع من السعادة و المرح مما يؤثر عليهم بإيجاب في حياهم اليومية

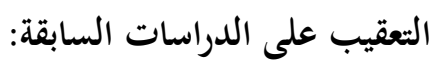
اتفقت هذه الدراسة مع الدراسات السابقة في أهمية ممارسة الأنشطة الترويحية للمسنات في وقت الفراغ، حيث بند

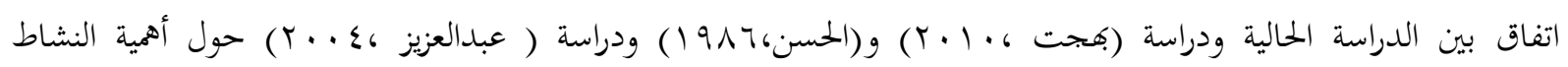




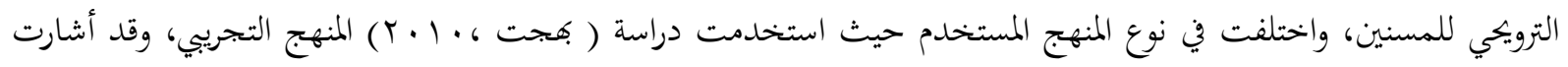

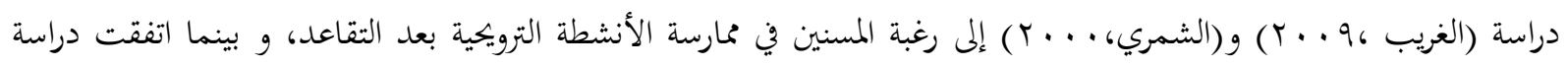

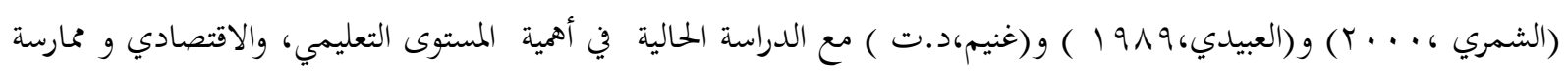
الأنشطة المختلفة لكبار السن، وأهمية ملكية السكن وممارسة الأنشطة المختلفة، كما استفادت هذه الدراسة من دراسة (الحسن ، ،1911) في التعرف على قائمة بالأنشطة المفضلة لكبار السن والتي تمارس في وقت الفراغ، كما استفادت من دراسة(الغريب ،9 . . ץ) في توضيح أسباب تفضيل كبار السن للأنشطة الترويحية، وكذلك أشارت دراسة (خليفة والحسن ، ـ99 1 ) أن ما يمنع أفراد الأسرة من المشاركة في قضاء وقت الفراغ عدم وجود خصوصية للأسرة في مكان الترويح. كما استفادت من دراسة (العبيدي،919 19) في معرفة العوامل التي تساعد المسنين على التكيف بعد التقاعد مثل: مزاولة الأنشطة الترويحية، وكذلك استفادت من الدراسات السابقة بطرح عدد من المفاهيم المتعلقة بأوضاع المسنين كالحالة الصحية ، والحالة الاجتماعية، والاقتصادية، حيث طرحت وبينت الدراسات السابقة علاقة هذه المفاهيم بممارسة الأنشطة المختلفة، كما طرحت العديد من المشكلات الأسرية والاجتماعية المرتبطة بالمسنات مما يشير إلى المعوقات التي تواجهها المسنات في الاستفادة من الأنشطة الترويحية وهو ماتمدف له هذه الدراسة. النتائج:

أوضحت نتائج الدراسة الحالية أن غالبية المشتركات في مركز الملك سلمان الاجتماعي من المتعلمات تعليم جامعي

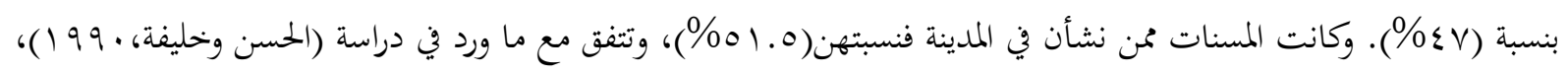
في أن سكان الحضر أكثر ميلا لممارسة الأنشطة من سكان الريف، واتضح كذلك أن أغلبية أفراد العينة متزوجات فقد بلغت نسبتهن (7 . ro\%) وهذا يدل على أن المسنات لديهن روابط أسرية، والحالة الزواجية مهمة في ممارسة المسنات للأنشطة التوويحية؛ لأن البعض منهن ينصرف عن ممارسة أنشطة معينة لأهما تحتاج وقتًا كبيرًا وهن ملتزمات بأزواجهن وأبنائهن وكثرة الالتزمات والارتباطات الأسرية الأخرى، كما يلاحظ ارتفاع نسبة الأرامل حيث بلغت نسبتهن(V.ب؟\%\%) وترى الباحثة أن الحالة الزواجية تؤثر إما في المشاركة في الأنشطة الترويحية أو عدمها، فتردد المسنات الأرامل على مركز الملك سلمان الاجتماعي؛ حيث تفتقدن للشريك أو الأبناء، وقلة زيارة الأهل والصديقات لهن وطول وقت الفراغ لديها، وهذا يتفق مع ما ورد في دراسة (غنيم، د.ت) في أن غالبية المترددين على المراكز الاجتماعية من المسنين الأرامل، أما المتزوجات يترددن على مركز الملك سلمان الاجتماعي بتشجيع 
من الزوج ودعم منه حيث إفن يمارسن هذه الأنشطة في غياب الزوج عن المنزل. ونلاحظ تأثير المستوى الاقتصادي في المشاركة بالأنشطة الترويحية وهذا يشير إلى ضرورة توعية المجتمع بإيجاد بدائل لشغل وقت فراغ المسنات بشكل عام، فغالبية المشتركات في مركز الملك سلمان من أصحاب الدخول المتوسطة والمرتفعة، كما تمارس غالبية المشتركات بمركز الملك سلمان أنشطة رياضية بنسبة(00\%) وذلك بسبب الوعي الصحي لديهن بأهمية النشاط الرياضي،وكذلك الأنشطة الثقافية قد بلغت نسبة (هب\%)وترى الباحثة إقبال المسنات على الأنشطة الثقافية وحرصهن على التزود بأنواع المعارف واكتساب المهارات المختلفة وتنمية مهارات

الحوار والمناقشة، ونلاحظ أن أعلى نسبة لمن تمارس الأنشطة الرياضية فقد بلغت (؟.00\%)، أما من يمارسن الأنشطة الثقافية

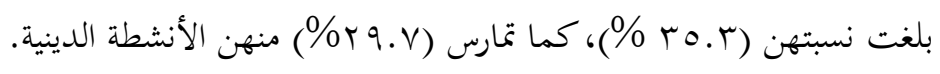

وترى الباحثة سبب ممارسة غالبية المشتركات بمركز الملك سلمان الاجتماعي للرياضة والأنشطة الثقافية، أن غالبيتهن تعليمهن جامعي، مما يشير إلى زيادة وعيهن بأهمية الرياضة وحسب ما ورد في دراسة(هجت · · ·) من أن ممارسة الرياضية تؤدي إلى تحسين الصحة الجسدية والنفسية. ، فقد بلغت نسبة من تقضي وقت فراغها بالأعمال المنزلية (ه.بr\%)، ومن يشاهدن التلفزيون في وقت فراغهن بلغت نسبتهن(؟؟٪\%)، وأما من يستمعن للمذياع في وقت فراغهن بلغت نسبتهن(ع . ع \%)، وبلغت نسبة ( ^. . ه\%) منهن وقت فراغهن بالصلاة وقراءة القرآن، أما من يقضين وقت الفراغ بحضور

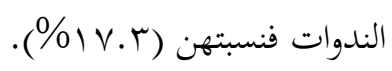

\section{أولاً: توصيات خاصة بمركز الأمير سلمان الاجتماعي.}

(1) تخفيض رسوم الاشتراك في المراكز وجعلها بأسعار تتناسب مع الجميع.

ץ ) توفير مشرفين مختصين أثناء تأدية المسنات للرياضة .

ץ) توفير الصيانة الدائمة وخاصة للمسابح.

ع) إقامة أنشطة رياضية تتناسب مع ميول وابتاهات المسنات وحالتهن الصحية .

\section{ثانيًا: توصيات خحاصة لوزارة الشؤون الاجتماعية.}

() توفير مراكز اجتماعية ترفيهية ورياضية خحاصة بالمسنات، وبحهزة بكافة الخحدمات الطبية والخدماتية. 
Y) إقامة مراكز اجتماعية منتشرة في معظم الأحياء؛ لتتمكن غالبية المسنات من الذهاب إليها خاصة في الأحياء الشعبية. r) توفير الأساليب الإعلامية المختلفة لتعريف المسنات بالبرامج المتوفرة لمن وكيفية الاستفادة منها . ثالثًا: توصيات خاصة للمجتع السعودي.

1) القيام بحملات توعوية تبين أهمية شغل وقت الفراغ للمسنات بالأنشطة الرياضية وإيضاح أهميتها وفوائدها للصحة النفسية

$$
\text { والجسدية. }
$$

Y (Y) توضيح ماهي مرحلة الشيخوخة والتغيرات التي تطرأ على الأفراد في هذه المرحلة وأهم الاحتياجات التي تلزهم. r 


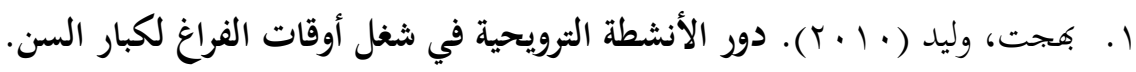

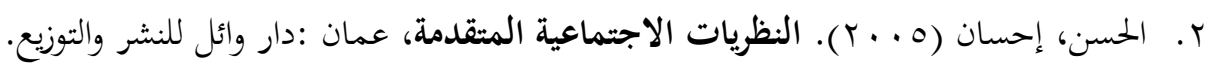

r. الحسن، إحسان (9 . . Y).مناهج البحث الاجتماعي، عمان :دار وائل للنشر والتوزيع · ع. . الحمامي، عحمد (7 (191) . الترويح وأوقات الفراغ في المجتمع المعاصر، مكة المكرمة.

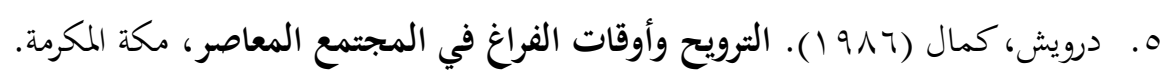
ج. السدحان، عبدالله ناصر (1991). الترويح وأوقات الفراغ، العبيكان، الرياض. V. السدحان، عبدالله ناصر (1999). روعاية المسن في المملكة العربية السعودية. .

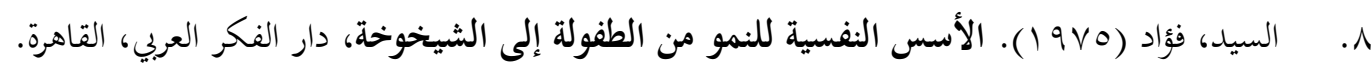

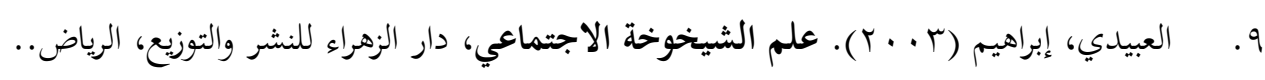

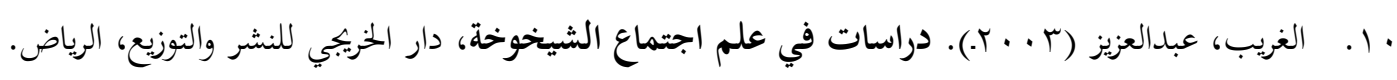

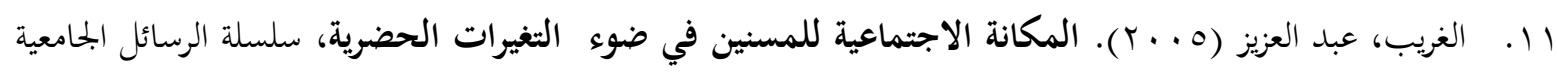

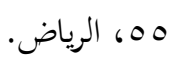

ثالثا: الرسائل العلمية

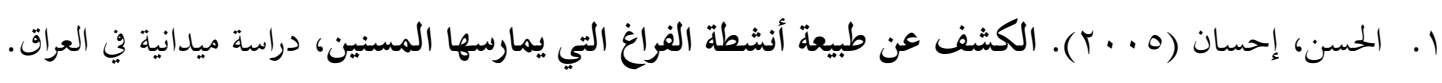

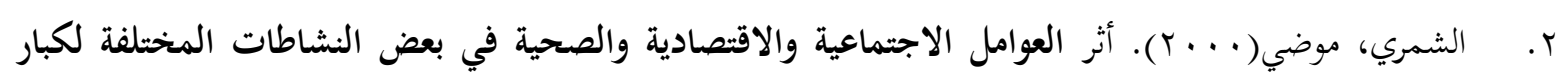

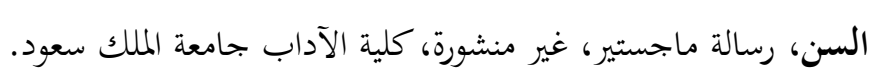
r. عبدالباقي، ثناء و خير الله، علية (د.ت). دراسة مقارنة للبرنامج الترويحي في كل من دار المسنين في محافظة الغربية ومحافظة القاهرة لوضع برنامج ترويحي مقترح. ع. عبدالعزيز، بلال وعبدالرازق، وليد (ع . ب). التحديات التي تواجه كبار السن في ممارسة أنشطة الترويح الرياضي بالأندية. ه. المهندس، سهير (ع (91). أثر برنامج ترويمي رياضي على بعض الأجهزة الحيوية للمسنين.. 


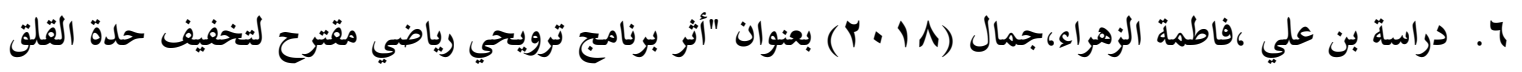
عند كبار السن " الجزائر مجلة الباحث في العلوم الانسانية العدد (بس). المراجع الإلكترونية: الم

http://www.mas-pssc.com/articles: 1. موقع مركز الملك سلمان الاجتماعي

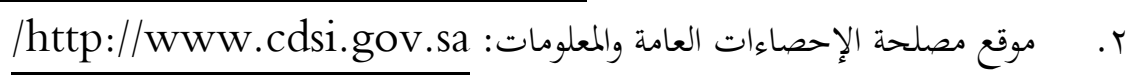

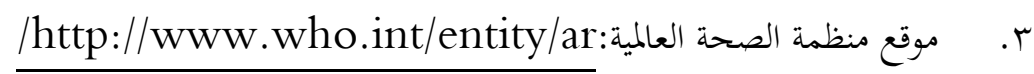

